\title{
COMPORTAMENTO DA HABILIDADE FUNCIONAL EM LONGEVOS 4 ANOS ANTES E DURANTE A COVID-19: ESTUDO AMPAL
}

Josemara de Paula Rocha; Pontifícia Universidade Católica do Rio Grande do Sul (PUCRS); josemara.rocha@hotmail.com Marlon Cássio Pereira Grigol; PUCRS; marlonfisio@gmail.com

Álvaro Luiz Fortes; PUCRS; alvarolforte@gmail.com Ana Paula Tiecker; PUCRS; anapaulatiecker@hotmail.com Renata Breda Martins; PUCRS; nutri.renatamartins@gmail.com Viviane Maura Rubert; PUCRS; vivirubert@hotmail.com Ângelo José Gonçalves Bós; PUCRS; angelo.bos@pucrs.br - Projeto de extensão Atenção Multiprofissional ao Longevo (AMPAL) da PUCRS, Porto Alegre, Brasil - Escola de Medicina da PUCRS, Porto Alegre, Brasil

\section{RESUMO}

Introdução: A habilidade funcional (HF) é a interação entre a capacidade intrínseca e o ambiente. Pouco se sabe sobre o declínio da HF em nonagenários e centenários e o seu efeito durante a COVID-19. Objetivo: Investigar mudança na HF decorrentes do isolamento social. Métodos: Estudo longitudinal e observacional. Nonagenários e centenários do estudo Atenção Multiprofissional ao Longevo foram avaliados em 4 momentos: visita domiciliar em 2016, 2017 e 2018 e não-presencial entre abril e agosto de 2020. Avaliando a HF: facilidade de realizar 5 atividades cotidianas em quatro níveis: $3=$ fácil, $2= \pm$ fácil, $1=$ difícil e $0=$ não consegue, totalizando entre 15 e zero pontos. Em 2020 , a HF foi questionada quanto a condição na entrevista e antes de 15/03/2020. As médias das HF foram comparadas entre as avaliações. Resultados: Dos 31 participantes $74 \%$ eram mulheres e média

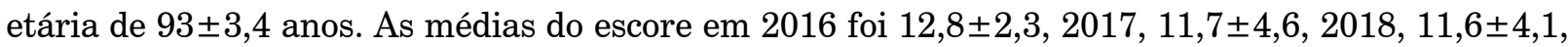
e 10,4 $\pm 3,9$ antes de $15 / 03$, e 10,8 $\pm 2,9$ pontos no momento atual. Observaram-se diferentes comportamentos funcionais: a maioria dos longevos se manteve estável (menor declínio) durante os anos de acompanhamento. Participantes com menor pontuação apresentaram maior declínio em relação aos com maior HF inicial. Conclusão: Observamos pouca alteração no comportamento da HF nos 5 primeiros meses de quarentena. A perda da HF ao longo dos anos, permitiu observar diferentes padrões de comportamento relacionados ao estilo de vida e controle clínico das multimorbidades.

Palavras-chave: Idoso de 80 Anos ou mais; Saúde Pública; Atividades Cotidianas; COVID-19; Pandemias.

Agradecimentos: O presente trabalho foi realizado com apoio da Coordenação de Aperfeiçoamento de Pessoal Nivel Superior - Brasil (CAPES) - Código de Financiamento 001. 